\title{
BMJ Open Fall and risk factors for veterans and non-veterans inpatients over the age of 65 years: 14 years of long-term data analysis
}

\author{
Huey-Jen Perng, ${ }^{1}$ Yu-Lung Chiu, ${ }^{2}$ Chi-Hsiang Chung, ${ }^{3}$ Senyeong Kao, ${ }^{1,2}$ \\ Wu-Chien Chien ${ }^{1,3}$
}

To cite: Perng H-J, Chiu Y-L, Chung $\mathrm{C}-\mathrm{H}$, et al. Fall and risk factors for veterans and nonveterans inpatients over the age of 65 years: 14 years of longterm data analysis. BMJ Open 2019;9:e030650. doi:10.1136/ bmjopen-2019-030650

- Prepublication history and additional material for this paper are available online. To view these files, please visit the journal online (http://dx.doi. org/10.1136/bmjopen-2019030650).

Received 27 March 2019 Revised 08 August 2019 Accepted 19 August 2019

Check for updates

(C) Author(s) (or their employer(s)) 2019. Re-use permitted under CC BY-NC. No commercial re-use. See rights and permissions. Published by BMJ.

${ }^{1}$ Graduate Institute of Life Sciences, National Defense Medical Center, Taipei, Taiwan

${ }^{2}$ School of Public Health, National Defense Medical Center, Taipei, Taiwan

${ }^{3}$ Department of Medical

Research, Tri-Service General Hospital Taipei, National Defense Medical Center, Taipei, Taiwan

Correspondence to

Professor Wu-Chien Chien; chienwu@ndmctsgh.edu.tw

\section{ABSTRACT}

Introduction Falls are one of the most important causes of injuries and accidental deaths among this segment of over the age of 65 years.

The long-term follow-up study of fall-related injuries was conducted in elderly veterans over the age of 65 years, and the risk of falls in veterans and non-veterans was compared.

Methods This study used the National Health Insurance Research Database for the period from 2000 to 2013 in Taiwan. This longitudinal study tracked falls in veterans over the age of 65 years, designated a control group (non-veterans), using 1:2 pairing on the basis of sex and time receiving medical care, and used Cox regression to analyse and compare the risk of falls among veterans and non-veterans.

Results This study subjects consisted of 35454 of the veterans had suffered falls $(9.5 \%)$, as had 55037 of the non-veterans $(7.4 \%)$. After controlling for factors such as comorbidities/complications, the veterans had 1.252 times the risk of falls of the non-veterans. Furthermore, among persons in the 75-84 years old age group, veterans had 1.313 times the risk of falls of non-veterans, and among persons with mental illnesses and diseases of the eyes, veterans had 1.300 and 1.362 times the risk of falls of non-veterans. In addition, each veteran had an average of 4.07 falls during the 2000-2013 period, which was significantly higher than in the case of non-veterans (3.88 falls).

Conclusions Veterans' risk of falls and recurrent falls were both higher than those of non-veterans, and age level, comorbidities/complications and level of low urbanisation were all important factors affecting veterans' falls. The responsible authorities should, therefore, use appropriate protective measures to reduce the risk of falls and medical expenses in high-risk groups.

\section{INTRODUCTION}

Falls are the second leading cause of death among accidental injuries worldwide. According to 2018 WHO data, as many as 646000 persons die from falls annually, and elderly persons over the age of 65 constitute the age group with the highest incidence of fall-related deaths. ${ }^{1}$ In Taiwan, according to
Strengths and limitations of this study

- This is the first nationwide population-based cohort study to assess the falls injury associations between veterans and non-veterans

- The strengths of this study include a sufficiently large research sample and a tracking period of 14 years, as well as the ability to compare the risk of falls among veterans and non-veterans and confirm factors affecting falls in veterans.

- This study cohort is large enough to examine each risks of fall injury among subgroups.

- The limitation of this study is the lack of information on the detailed patient characteristics and could not obtain other important information related to falls (such as the living environment, muscular endurance and degree of disability).

the 2017 annual report on the cause of death statistics issued by the Ministry of Health and Welfare, Executive Yuan, falls were the second leading cause of death among accidental injuries in 2017. ${ }^{2}$ According to data from the Veterans Affairs Council, as of the end of 2017, veterans over the age of 65 years accounted for approximately $50 \%$ of all veterans and $6.14 \%$ of Taiwan's elderly population over the age of 65 years. ${ }^{3}$ Furthermore, the health insurance participation of veterans over the age of 65 years accounts for $7.7 \%$ of that of all persons over the age of 65 years in Taiwan. ${ }^{4}$ As a consequence, veterans constitute an important subgroup of elderly persons with relatively high healthcare needs.

According to research conducted in the USA, in 2012, 3.2 million people were injured in non-fatal falls (incurring medical expenses of US\$30.3 billion), and 24190 people died due to falls (incurring direct medical expenses of US $\$ 616.5$ million); these figures increased to US\$31.3 billion and US\$637.5 million in 2015 , and the incidence 
of falls and total medical expenses increased with age. ${ }^{5}$ A research survey of elderly people in the USA found that $78 \%$ of falls could be attributed to two or more risk factors, and the greater the number of risk factors was, the greater the probability of a fall ${ }^{6}$; risk factors for falls include sex, age, socioeconomic status, environment and physiological condition (poor vision, chronic illness and poor balance) ${ }^{7-9}$ According to the 2014 research of Clegg et $a l,{ }^{10}$ risk factors for falls include a poor living environment, use of multiple medications, lack of vitamin $\mathrm{D}$, comorbidities, sarcopenia or frailty and impaired sensory system. In addition, a 2017 cross-sectional study (Paliwal et $a l^{11}$ ) of the relationship between chronic disease and falls among community seniors over the age of 65 years, involving the use of the Behavioural Risk Factor Surveillance System, found that the incidence of falls during the previous 1-year period among people with such chronic diseases, such as stroke (adjusted $\mathrm{OR}=1.61$ ), chronic kidney disease (adjusted $\mathrm{OR}=1.27$ ), arthritis (adjusted $\mathrm{OR}=1.61$ ), depression (adjusted $\mathrm{OR}=2.26$ ) and diabetes (adjusted $\mathrm{OR}=1.32$ ) was uniformly higher than in people without these diseases and whether assistive equipment was used was also a factor affecting falls. ${ }^{12}$ In Taiwan, according to Chien et $a l,{ }^{13}$ the 518601 elderly persons hospitalised for injuries between 2005 and 2007 had an average age of 76.1 , and 209860 of these people (40.5) had fall-related injuries, making falls the chief cause of injuries. ${ }^{13}$ Furthermore, in a study analysing factors associated with falls among 940 veterans at four veteran's care centres in eastern Taiwan during the 2009-2010 period, $\mathrm{Ku}$ et al found that falls and recurrent falls had incidences of $17.2 \%$ and $6.9 \%$, respectively; age, depression, stroke, gouty arthritis and cataracts were independent risk factors for falls, and depression was a risk factor for recurrent falls (adjusted OR=1.22) ${ }^{14}$ In summary, a few large studies have examined veterans as subjects, and most of the research consisted of cross-sectional studies and questionnaire surveys. In contrast, we employed a long-term longitudinal study to analyse the risk of fall-related injuries, and we hope that this approach can help mitigate the shortcomings of the foregoing literature.

In Taiwan, after their discharge, veterans who spent their careers in the armed forces to contribute to their country face diseases of old age, and their fall-related injuries are also an issue of concern. Jobless veterans receive various benefits from the Veterans Affairs Council and enjoy exemption from health insurance copayments. ${ }^{3}$ While some literature has investigated issues such as chronic diseases acquired after discharge,${ }^{15}$ mental illness, ${ }^{16}$ life satisfaction ${ }^{17}$ and medical utilisation ${ }^{18}{ }^{19}$ in some elderly veterans with wartime experience, there has been an absence of long-term follow-up studies of fall-related injuries in veterans. What is the risk of a fall among veterans? Does the risk of a fall among veterans differ from that among the general population? This study sought to investigate these questions. Accordingly, veterans over the age of 65 years during the 2000-2013 period were included as subjects in a long-term follow-up epidemiological study of fall-related injuries, and the risks of falls among veterans and non-veterans were compared.

\section{METHODS}

\section{Data sources}

Taiwan's National Health Insurance (NHI), which was introduced in 1995, records the medical data of all insured people, covering more than $99 \%$ of the 23 million people in Taiwan. As a result, the NHI data constitute an important resource for research concerning clinical medicine and public health. ${ }^{20}{ }^{21}$ Because the outpatient and emergency care files in the National Health Insurance Research Database (NHIRD) provide only injury diagnostic data, but not the causes of injuries, while hospitalisation files provide information concerning the causes of injuries, this study accordingly performed string analysis of data in the NHIRD's 'inpatient expenditures by admissions (DD),' 'registry for contracted medical facilities (HOSB),' 'major injury and illness (HV)' and 'underwriting data details (ID)' files for the period from 2000 to 2013.

\section{Patient and public involvement}

Participants were not involved in the design or conduct of this study.

\section{Study design and participants}

This study included 'jobless' veterans ('veterans') over the age of 65 years as the members of the case group. To ensure that the cases represented newly occurring falls, we excluded falls during the 1997-1999 period, and the study period was extended from 1 January 2000 to 31 December 2013 (tracking end point). We employed a matching control design in which 1:2 pairing was performed on the basis of the veterans' sex, age and time receiving medical care, and we selected non-veterans with the corresponding criteria to serve as the control group. To obtain a sufficient number of non-veteran subjects aged 65 years and older, the tolerance was set at 0.25.

\section{Event occurrence}

All cases were tracked to a fall accident (International Classification of Diseases, Ninth Revision, Clinical Modification (ICD)-9-CM E code 880-888), loss of case during the research period (loss to follow-up) or to the research end point on 31 December 2013.

\section{Standards and definitions}

The ages of the subjects in this study were the ages when the event (fall) occurred. The three age groups in this study consisted of 65-74 years, 75-84 years and over 85 years. The severity of falls was judged on the basis of a trauma severity greater than 16 points (Injury Severity Score (ISS >16) in the major injury and illness category in the major injury and illness (HV) files. Injury Severity Score (ISS): this anatomic rating system divides the human body into six anatomic parts (head/neck, face, thorax, abdomen, extremity and external). Each section is scored 
from 1 to 5 (a higher score indicates greater severity), and the three parts that are the most severe are selected. The respective scores are squared and then added together; the result is the ISS score of the respective patient $(0-75$, in which an ISS score of $>16$ represents severe injuries). ${ }^{22}$ The ISS of the study can be obtained from the NHIRD. ${ }^{23}$ Because comorbidities/complications, ${ }^{10}{ }^{11}{ }^{18}$ mental illness ${ }^{11} 162425$ and diseases of the eyes ${ }^{11} 1426$ are also risk factors for falls in the elderly, to clarify the influence of illnesses on falls among veterans and non-veterans, this study included commonly seen comorbidities/complications of the elderly in its regression model and controlled for mental illness (ICD-9-CM 290-319) and diseases of the eyes (ICD-9-CM 360-379). In addition, among environmental variables, the level of urbanisation was classified as high, moderate and low; the urbanisation level of residence was defined according to the population and various indicators of the level of development. High was defined as a population of $>1250000$ and a specific designation as a political, economic, cultural and metropolitan development. Medium was defined as a population between 500000 and 1249999 and as playing an important role in the political system, economy and culture. Low was defined as a population $<499999 .{ }^{27} 28$ The season was classified as spring (March-May), summer (June-August), fall (September-November) and winter (December-February), the grade of hospital where the subject received care was classified as a medical centre or a non-medical centre and the hospital was classified as a veteran hospital or a non-veteran hospital. In accordance with the external factor code (ICD-9-CM E-code (E880-888)), the causes of injuries were classified as three types: fall from a height (E800-884), fall on the same level (E885-886) and other falls (E887-888). Recurrent falls were defined as two or more falls occurring within the research period (from 2000 to the end of 2013).

\section{Statistical analysis}

This study included veterans over the age of 65 years as research subjects, tracked the cause of their falls during the 2000-2013 period and type of injury and found factors affecting the occurrence of their falls. Data analysis was performed using SPSS V.22 statistical software; the $\chi^{2}$ test was employed to compare categorical variables, and the t-test was used to compare continuous variables in the two groups. Factors affecting falls were analysed by Cox's regression, while HRs, 95\% CIs and KaplanMeier survival curves were used to extract differences between the veteran and non-veteran groups. A $p$ value $<0.05$ was considered the standard for the assessment of significance.

\section{RESULTS}

Figure 1 shows the case selection (inclusion and exclusion) and a tracking result flow chart. During the 20002013 period, a total of 2974621 elderly people over the age of 65 years were hospitalised in Taiwan; after excluding 163737 people who were hospitalised for falls during the period from 1997 to 1999 , a total of 2810884 persons remained, which included 374057 veterans and 748114 non-veterans over the age of 65 years.

Table 1 shows the basic characteristics of the entire sample of 1122171 people (374057 veterans and 748114 non-veterans) at the tracking end point. The reported ages of the subjects in this study (table 1) were the ages when the event (fall) occurred: on average, these ages were 78.0 \pm 7.2 years old (veterans: $80.1 \pm 6.5$; non-veterans: $77.0 \pm 7.3$ ). The mean follow-up duration among all subjects in this study (2000-2013) was 7.7 years. By age group, the mean follow-up was 8.1 years among those aged 65-74 years, 7.5 years among those aged $75-84$ years and 6.3 years among those aged 85 years and above. The time to fall (the event) since observation among the subjects was 4.5 years on average. For the three age groups, the time to fall was 5.1, 4.1 and 2.7 years, respectively. On average, $1.7 \%$ of subjects experienced recurrent falls. For the three age groups, this proportion was $1.2 \%, 2.0 \%$ and $2.1 \%$, respectively. The abovementioned data show that the duration of follow-up was longer (8.1 years) in the younger population (65-74 years old), and the ratio of recurrent falls was relatively low in this population as well $(1.2 \%)$. However, the duration of follow-up was relatively short (6.3 years) for the old population ( $\geq 85$ years old), and the ratio of recurrent falls in this age group was relatively high $(2.1 \%)$ (data not shown). The percentage of veterans who suffered falls was significantly higher than that of non-veterans $(9.5 \%$ vs $7.4 \%, \mathrm{p}<0.001)$, and they also had a significantly higher probability (risk) of falls during the first year than non-veterans (log-rank test, $\mathrm{p}<0.001$ ) (figure 2). In addition, a significantly higher percentage of veterans than non-veterans lived in areas with a moderate level of urbanisation and received care at a medical centre or a veteran's hospital.

Table 2 shows the results of the univariate and multivariate analysis for factors affecting falls. After controlling for factors such as comorbidities/complications, veterans' subsequent (14 years) risk of falls was 1.252 times $(\mathrm{p}<0.001)$ that of non-veterans; the subsequent risk of falls among those in the 75-84 and 85 years old and over age groups were 1.081 times $(\mathrm{p}<0.001)$ and 1.057 times $(p<0.001)$ that of people in the $65-74$ years old age group, and the subsequent risk of falls of people living in areas with moderate and low urbanisation were 1.170 times $(\mathrm{p}<0.001)$ and 1.136 times $(\mathrm{p}<0.001)$ that of people living in areas with high urbanisation. People with mental illness had a risk of falls 1.730 times $(\mathrm{p}<0.001)$ that of persons not suffering from mental illness. People suffering from diseases of the eyes had 1.225 times $(p<0.001)$ the risk of falls of people not suffering from diseases of the eyes.

Table 3 shows the results of a stratified analysis of the variables and reveals that, after controlling for factors such as comorbidities/complications, regardless of sex, age, season, level of urbanisation, hospital grade, whether hospitalisation occurred at a veteran's hospital, severity of the injury, whether the subject suffered from mental 


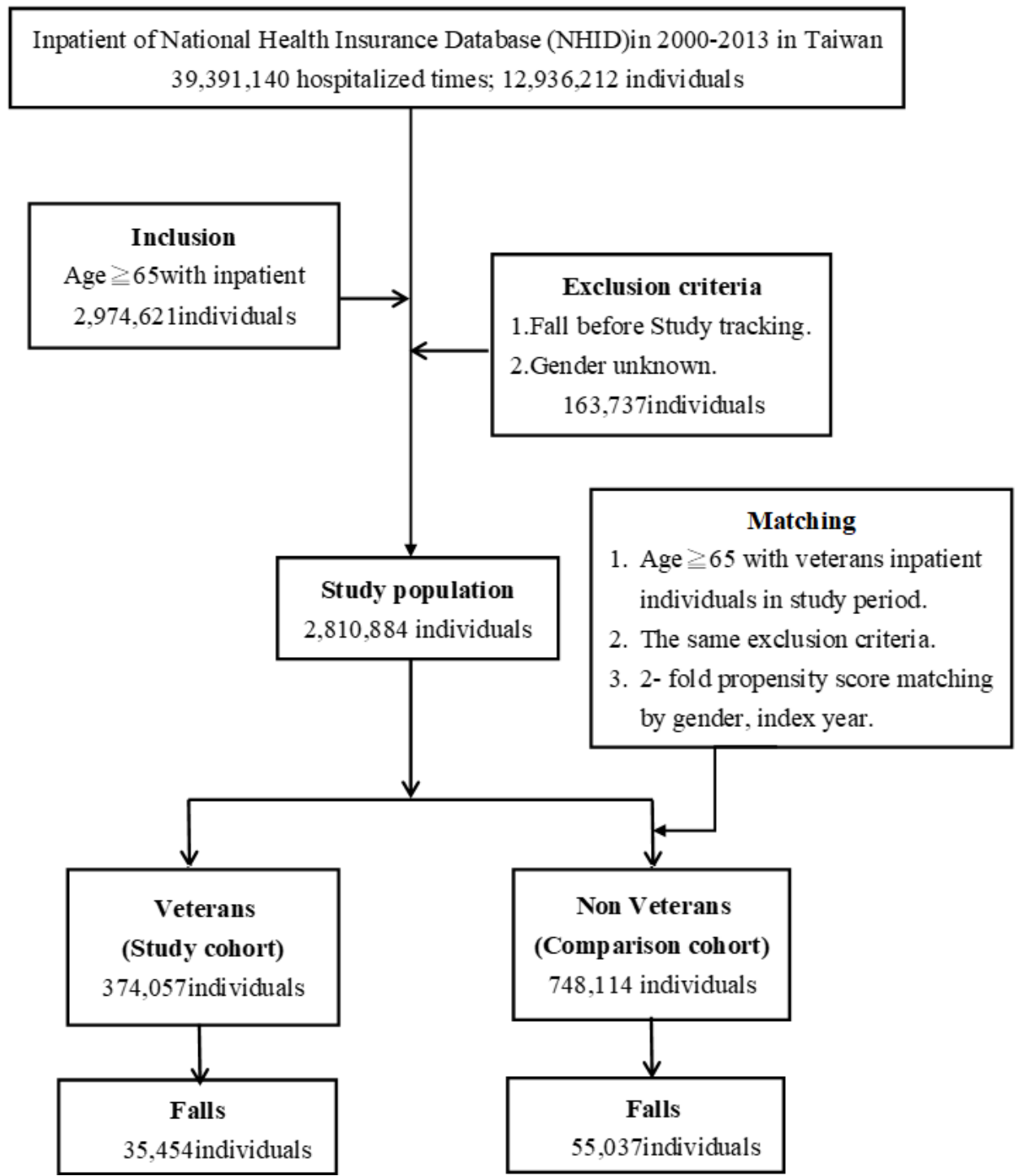

Figure 1 The flow chart of study sample selection from National Health Insurance Research Database in Taiwan.

illness or whether the subject suffered from diseases of the eyes, veterans had a higher risk of falls than non-veterans, and their risk was 1.155-1.478 times higher than that of non-veterans. In particular, in the male group, veterans had 1.299 times $(\mathrm{p}<0.001)$ the risk of falls of non-veterans; in the 75-84years old age group, veterans had 1.313 times $(\mathrm{p}<0.001)$ the risk of falls of non-veterans; among those with diseases of the eyes, veterans had 1.362 times $(p<0.001)$ the risk of falls of non-veterans, and among those suffering from mental illness, veterans had 1.300 times $(p<0.001)$ the risk of falls of non-veterans. Furthermore, among comorbidities/complications, in the atherosclerotic disease group, veterans had 1.478 times $(p<0.001)$ the risk of falls of non-veterans, and in the group with paralysis of the limbs, veterans had 1.356 times $(p<0.001)$ the risk of falls of non-veterans.

In online supplementary table $\mathrm{S} 2$, model 1 shows that veterans had 1.252 times $(\mathrm{p}<0.001)$ the risk of falls of non-veterans after controlling for factors such as comorbidities/complications, and model 2 shows that when the stratification was performed based on the dependent variable (cause of fall-related injury), veterans had 1.171 times $(p<0.001)$ the risk of falls from a height of non-veterans, and 1.193 times $(p<0.001)$ the risk of falls on the same level of non-veterans. Model 3 shows that when the stratification was performed based on the number of falls, veterans had 1.229 times $(\mathrm{p}<0.001)$ the risk of a single fall of non-veterans and 1.290 times $(p<0.001)$ the risk of recurrent falls of non-veterans.

\section{DISCUSSION}

This study was Taiwan's first long-term follow-up study seeking to gain an understanding of falls in veterans, and the results showed that 35454 veterans suffered falls $(9.5 \%)$ during the research period, while 55037 non-veterans suffered falls $(7.4 \%)$ during the same period, indicating that veterans had 1.252 times $(\mathrm{p}<0.001)$ the risk of falls of non-veterans. In a 2015 cross-sectional study of injuries in 287113 veterans and non-veterans receiving emergency care, veterans had a higher incidence of emergency care than non-veterans $(5.1 \%$ vs $4.0 \%$, p $<0.001),{ }^{29}$ 
Table 1 Characteristics of study in the endpoint

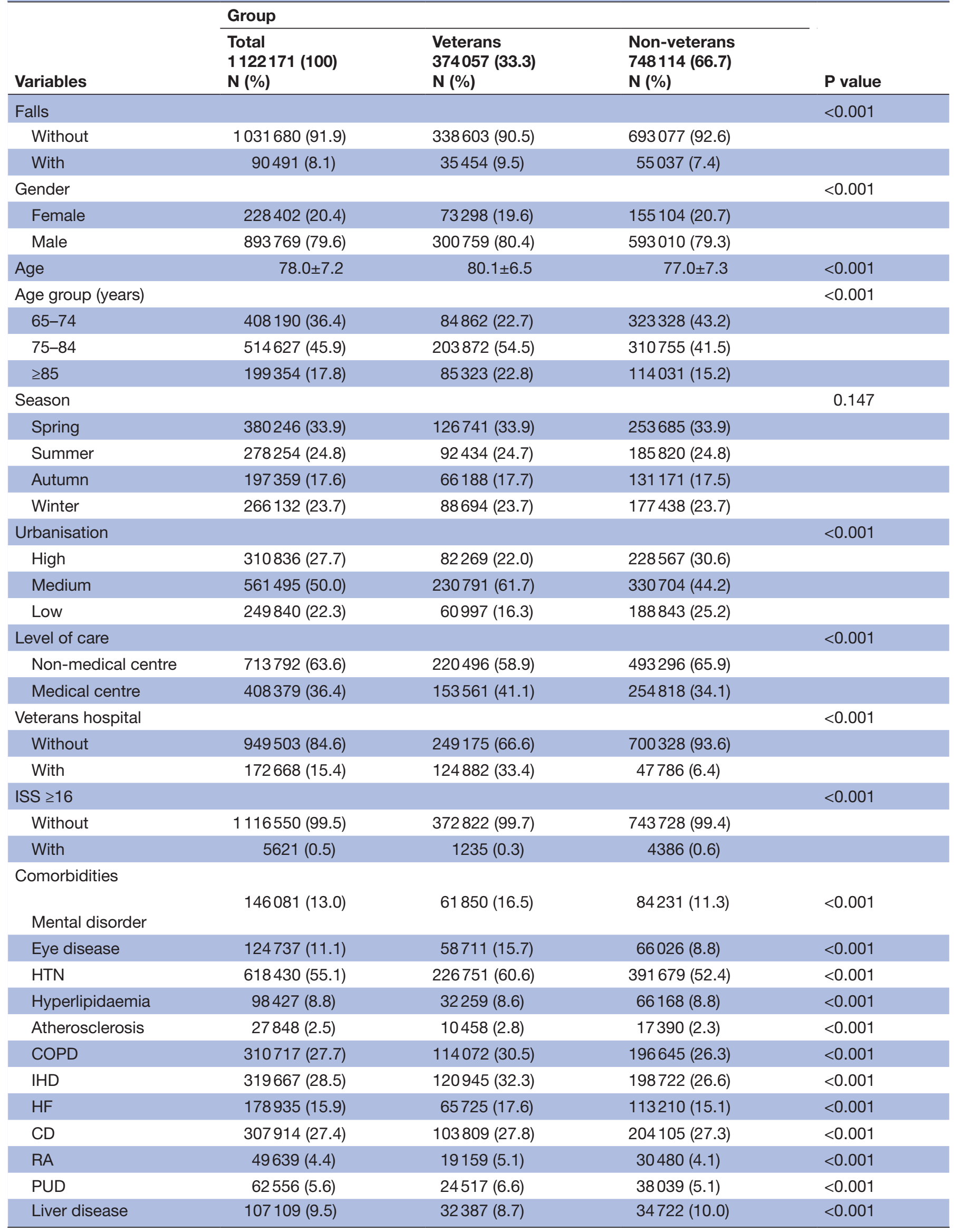


Table 1 Continued

\begin{tabular}{|c|c|c|c|c|}
\hline \multirow[b]{2}{*}{ Variables } & \multicolumn{3}{|l|}{ Group } & \multirow[b]{2}{*}{$P$ value } \\
\hline & $\begin{array}{l}\text { Total } \\
1122171(100) \\
N(\%)\end{array}$ & $\begin{array}{l}\text { Veterans } \\
374057 \text { (33.3) } \\
\text { N (\%) }\end{array}$ & $\begin{array}{l}\text { Non-veterans } \\
748114(66.7) \\
\text { N (\%) }\end{array}$ & \\
\hline DM & $336143(30.0)$ & 112864 (30.2) & 223279 (29.8) & $<0.001$ \\
\hline Haemiplegia & 55355 (4.9) & 17852 (4.8) & $37503(5.0)$ & $<0.001$ \\
\hline
\end{tabular}

$\chi^{2} /$ Fisher's exact test on category variables and t-test on continue variables. The comorbidities are listed in the online supplementary table S1.

$\mathrm{CD}$, cerebrovascular disease; CKD, chronic kidney disease; COPD, chronic obstructive pulmonary disease; DM, diabetes mellitus; HF, heart failure; HTN, hypertension; IHD, ischemic heart disease; ISS, injury severity score; PUD, peptic ulcer disease; RA, rheumatism.

which was consistent with the findings of this study. Moreover, another study of falls in veteran's care centres found a $17.2 \%$ incidence of falls,${ }^{14}$ which was higher than the incidence in this study $(9.5 \%)$. The study in question consisted solely of a self-completed questionnaire survey (concerning falls) of 940 veterans in eastern Taiwan, the sample was small and the study only investigated output information. In contrast, the present study focused on patients who had been hospitalised with confirmed physician's diagnoses and constituted a large sample, which may account for the differences in findings with the prior study. Most past research on veterans has consisted of cross-sectional studies or questionnaire surveys with a short study length and small sample size. There have been few longitudinal studies of falls in veterans. The findings of this study help to make up for the shortcomings of the aforementioned research.

A stratified analysis by age revealed that veterans at all three age levels had a greater risk of falls than non-veterans, and veterans in the 75-84years old age group had 1.313 times the risk of falls of non-veterans. In contrast, a 2009 study of inpatient medical utilisation by elderly fall patients over the age of 65 years indicated that the

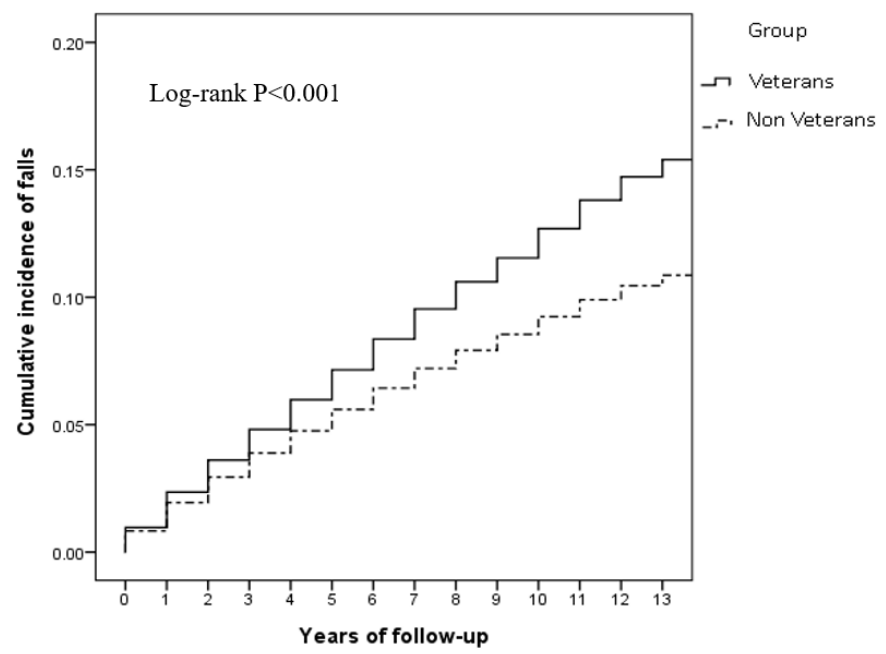

Figure 2 Kaplan-Meier for cumulative risk of fall in 14-year tracking stratified by veterans with log-rank test. largest proportion of the patients were in the 75-84years old age group $(46.5 \%),{ }^{30}$ but the study did not analyse veterans as a separate category. Furthermore, a 2016 paper concerning emergency care of injuries found that a higher percentage of male veterans receiving care for injuries were in the 75-84years old age group $(51.7 \%, \mathrm{p}<0.001)$ than the other age groups $(65-74$ years: $34.8 \% ; \geq 85$ years: $13.5 \%),{ }^{29}$ which was similar to the finding of this study (54.5\%); however, the previous study did investigate differences in risk of fall-related injuries between veterans and non-veterans. The present study discovered that veterans in the 75-84years old age group hospitalised for falls had a longer hospital stay than non-veterans (9.13 days vs 8.75 days), had slightly higher average inpatient medical expenditures than non-veterans (NT\$59800 vs NT\$59 500) and was a highrisk group for recurrent falls. According to data from the Veterans Affairs Council, most veterans in the 75-84 years old age group were senior veterans (born prior to 1934) and took part in the war of resistance against Japan ${ }^{3}$; it will be worthwhile to conduct a further longitudinal study determining whether the disabilities resulting from wartime service have caused these veterans to have a greater risk of falls than non-veterans.

The results of this study show that although veterans were older than non-veterans (80.1 vs 77.0 years old), their incidence of an ISS score of $\geq 16$ was lower than that of non-veterans $(0.3 \%$ vs $0.6 \%)$. A possible inferred cause is that veterans received complete military training while in service and hence could react more quickly and maintain a relatively ideal physical condition. (A reanalysis of the data showed that among the subjects who had fallen, the ratio of osteoporosis among the veterans and non-veterans was $4.8 \%$ vs $5.2 \%$, respectively $(\mathrm{p}<0.001$.) (See online supplementary table S3 for a cross-analysis of the two groups and osteoporosis.) In addition, the living environment of the veterans could offer better protection (such as soft floors, among others) and related healthcare professionals for most of the veterans (veteran homes) ${ }^{31}$ to offer immediate management and assistance in quickly sending them to the hospital for medical treatment as 
Table 2 Factors of falls by using multivariable Cox proportional hazard regression model

\begin{tabular}{|c|c|c|c|c|c|c|}
\hline Variables & Crude HR & $95 \% \mathrm{Cl}$ & $P$ value & Adjusted HR & $95 \% \mathrm{Cl}$ & $P$ value \\
\hline \multicolumn{7}{|l|}{ Groups } \\
\hline Non-veterans & Reference & & & Reference & & \\
\hline \multicolumn{7}{|l|}{ Gender } \\
\hline Female & Reference & & & Reference & & \\
\hline $65-74$ & Reference & & & Reference & & \\
\hline $75-84$ & 1.366 & 1.344 to 1.388 & $<0.001$ & 1.081 & 1.064 to 1.099 & $<0.001$ \\
\hline$\geq 85$ & 1.520 & 1.491 to 1.549 & $<0.001$ & 1.057 & 1.036 to 1.078 & $<0.001$ \\
\hline \multicolumn{7}{|l|}{ Season } \\
\hline Winter & 1.082 & 1.064 to 1.101 & $<0.001$ & 1.079 & 1.061 to 1.098 & $<0.001$ \\
\hline \multicolumn{7}{|l|}{ Urbanisation } \\
\hline High & Reference & & & Reference & & \\
\hline Medium & 1.250 & 1.231 to 1.273 & $<0.001$ & 1.170 & 1.149 to 1.190 & $<0.001$ \\
\hline Low & 1.439 & 1.418 to 1.472 & $<0.001$ & 1.136 & 1.113 to 1.160 & $<0.001$ \\
\hline \multicolumn{7}{|l|}{ Level of care } \\
\hline $\begin{array}{l}\text { Non-medical } \\
\text { centre }\end{array}$ & Reference & & & Reference & & \\
\hline Medical centre & 0.608 & 0.598 to 0.617 & $<0.001$ & 0.706 & 0.694 to 0.718 & $<0.001$ \\
\hline HTN & 2.073 & 2.043 to 2.104 & $<0.001$ & 1.560 & 1.535 to 1.585 & $<0.001$ \\
\hline Hyperlipidaemia & 1.210 & 1.185 to 1.235 & $<0.001$ & 0.890 & 0.871 to 0.909 & $<0.001$ \\
\hline Atherosclerosis & 1.337 & 1.291 to 1.385 & $<0.001$ & 1.064 & 1.027 to 1.102 & $<0.001$ \\
\hline COPD & 1.572 & 1.551 to 1.593 & $<0.001$ & 1.249 & 1.231 to 1.267 & $<0.001$ \\
\hline IHD & 1.550 & 1.529 to 1.571 & $<0.001$ & 1.120 & 1.117 to 1.101 & $<0.001$ \\
\hline HF & 1.535 & 1.512 to 1.559 & $<0.001$ & 1.096 & 1.078 to 1.114 & $<0.001$ \\
\hline$C D$ & 1.735 & 1.712 to 1.758 & $<0.001$ & 1.258 & 1.239 to 1.276 & $<0.001$ \\
\hline $\mathrm{RA}$ & 1.770 & 1.728 to 1.813 & $<0.001$ & 1.371 & 1.338 to 1.405 & $<0.001$ \\
\hline PUD & 1.632 & 1.596 to 1.668 & $<0.001$ & 1.139 & 1.113 to 1.165 & $<0.001$ \\
\hline Liver disease & 1.305 & 1.280 to 1.331 & $<0.001$ & 1.164 & 1.142 to 1.188 & $<0.001$ \\
\hline DM & 1.441 & 1.421 to 1.460 & $<0.001$ & 1.109 & 1.093 to 1.124 & $<0.001$ \\
\hline Haemiplegia & 1.475 & 1.439 to 1.511 & 0.027 & 1.029 & 1.003 to 1.055 & $<0.001$ \\
\hline CKD & 1.416 & 1.395 to 1.438 & $<0.001$ & 1.140 & 1.122 to 1.158 & $<0.001$ \\
\hline Cancer & 0.900 & 0.886 to 0.914 & 0.061 & 1.015 & 0.999 to 1.030 & $<0.001$ \\
\hline
\end{tabular}

Adjusted HR: adjusted for the variables listed in table 2. The comorbidities are listed in the online supplementary table s1.

AHR, adjusted HR; CD, cerebrovascular disease; CKD, chronic kidney disease; COPD, chronic obstructive pulmonary disease; DM, diabetes mellitus; HF, heart failure; HTN, hypertension; IHD, ischemic heart disease; ISS, injury severity score; PUD, peptic ulcer disease; RA, rheumatism. 
Table 3 Factors of falls stratified by variables listed in the table by using Cox proportional hazard regression model

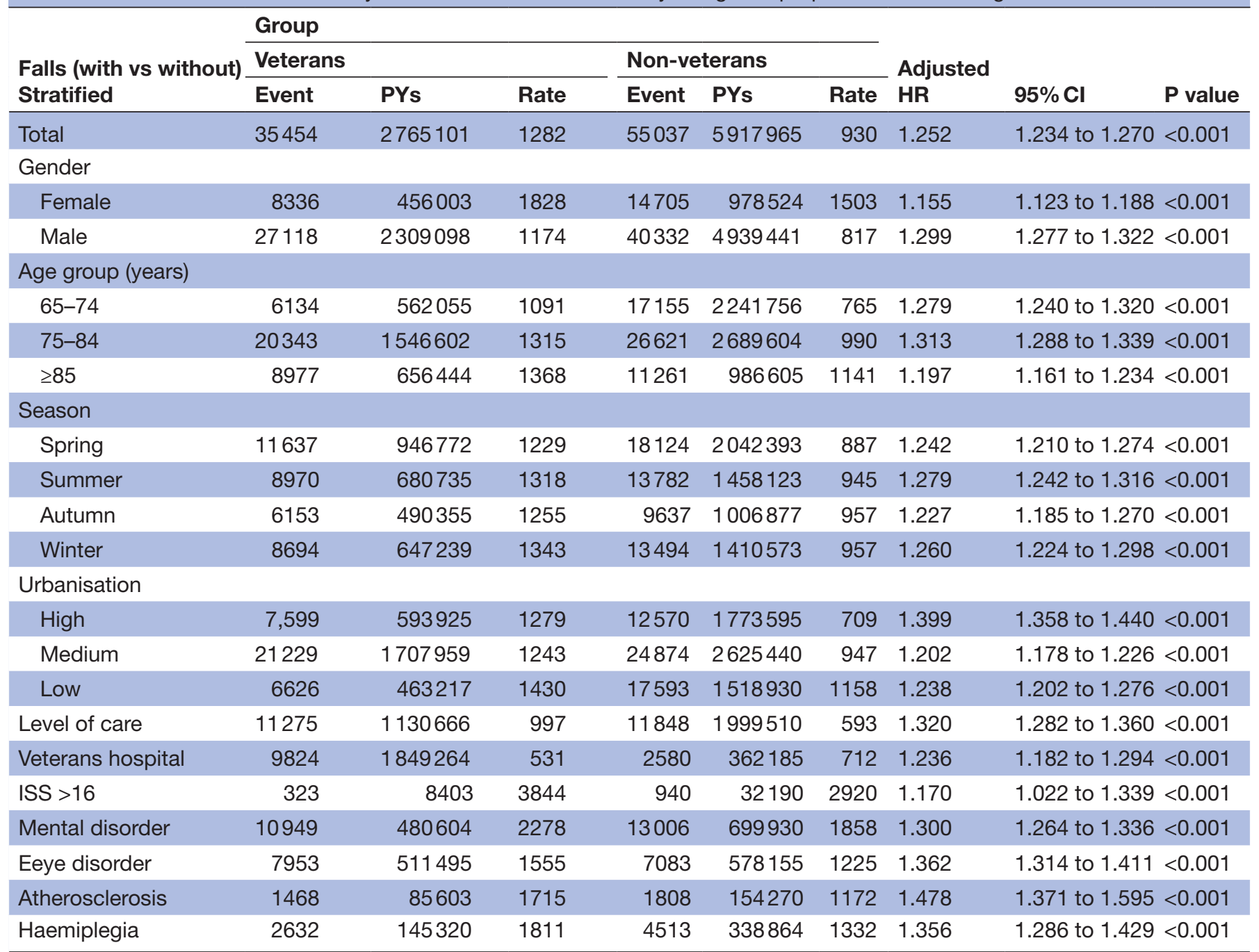

Adjusted HR: adjusted for the variables listed in table2; rate=per $100000 \mathrm{PYs}$.

The comorbidities are listed in theonline supplementary table S1.

ISS, Injury Severity Score; PYs, person years.

soon as they fall. This is why the incidence of veterans with more severe injuries (an ISS score of $\geq 16$ ) was lower than that of non-veterans $(0.3 \%$ vs $0.6 \%$, as shown in the table 1). Given the limitations of the secondary data, this type of correlation is worthy of further study.

The study results showed that low urbanisation is also a risk factor for falls among veterans. We further cross-analysed the extent of urbanisation versus mental disorders, and the results showed that the ratio of mental disorders among veterans living in areas with a relatively low extent of urbanisation was higher than that among veterans in highly urbanised areas $(24.0 \%$ vs $14.6 \%$; see online supplementary table S4). This finding is similar to that of a study among veterans in the USA (the incidence of mental disorders among veterans living in agricultural areas and that among those in urban areas was $23.69 \%$ and $16.68 \%$, respectively). The above study also indicated that fewer veterans in agricultural areas received psychotherapy than in urban areas. ${ }^{32}$ Therefore, providing mental healthcare services to veterans in areas with a low extent of urbanisation may be something that can be addressed by the Taiwan Veterans Affairs Council (VAC) for the current stage.

This study found that a significantly higher percentage of veterans suffered from mental illness than non-veterans $(16.5 \%$ vs $11.3 \%$; $\mathrm{p}<0.001)$. A 2014 retrospective study of the psychological treatment of veterans using data from the US Veterans Health Administration (VHA) healthcare system discovered that the percentage of veterans receiving psychological treatment increased with age, and the frequency of psychological treatment also increased with time. ${ }^{33}$ Our study found that veterans suffering from mental illness had 1.300 times the risk of falls of non-veterans. Past research has indicated that emotional disorders (such as depression and neurological disorders) may cause falls by affecting activities and the sense of balance. ${ }^{162425}$ This study's stratified analysis of the effect of mental illness further discovered that 
veterans with depression had 1.366 times the risk of falls of non-veterans (adjusted HR=1.366, 95\% CI 1.283 to 1.454 , $\mathrm{p}<0.001$ ), while veterans with anxiety disorder had 1.317 times the risk of falls of non-veterans (adjusted $\mathrm{HR}=1.317$, 95\% CI 1.201 to $1.443 ; \mathrm{p}<0.001$ ) (online supplementary file 1). Furthermore, depression (adjusted $\mathrm{HR}=1.938$, $\mathrm{p}<0.001,95 \%$ CI 1.793 to 2.094 ) (online supplementary table S6) was a predictor of recurrent falls in veterans; this result was somewhat similar to the findings of past research, which found that depression is a risk factor for falls in veterans and also for recurrent falls. ${ }^{14}$

A study of elderly persons in the community found that individuals with depression in conjunction with chronic diseases (cardiovascular disease, diabetes and arthritis) had a greater risk of falls than individuals who neither had depression nor suffered from chronic disease (3.95 times, 4.25 times and 9.66 times).$^{34}$ Further analysis in this study found that elderly individuals with depression together with Hypertention (HT) or Chronic obstructive pulmonary disease (COPD) or Cerebrovascular disease (CD) or Rheumatism (RA) had a greater risk of falls (2.262 times, 1.829 times, 1.867 times and 1.849 times) (online supplementary table S7) than those elderly individuals who neither had depression nor suffered from chronic disease.

The US Medical records of veterans reveal 'that one in three patients was diagnosed with at least one mental health disorder- $41 \%$ were diagnosed with either a mental health or a behavioral adjustment disorder, ${ }^{35}$ In addition, the research indicates that people with mental disorders (such as depression and anxiety) tend to develop negative sentiments and suffer from sleep disorders, among other symptoms. ${ }^{36}$ The presence of sleep disorders (such as insomnia and fewer hours of sleep) leads to deteriorated physical coordination and reactivity and, hence, tends to increase the risk of falls. ${ }^{37}$ Further data analysis in this study shows that the incidence of sleep disorders was higher among veterans than among non-veterans $(0.9 \%$ vs $0.7 \%$ ).

In addition, prior studies have pointed out that prescriptions for mental disorders (including antidepressants, antipsychotics, sedatives or tranquillisers) also increase the risk of falls. ${ }^{38-41}$ However, medication among veterans was not explored in this study and will require clarification in subsequent studies.

In summary, apart from physiological (physical) issues, mental illness in veterans is a hidden problem that nevertheless should be taken seriously. This study infers that because veterans lose their social status after discharge, may have few interpersonal interactions and may suffer from physiological stress due to the infirmity of old age, when veterans can no longer live independently, their unwillingness to leave their familiar environment and receive care in a veterans nursing home may be accompanied by mental illness such as depression and anxiety. The findings of this study support this phenomenon. In addition, the interaction of physiological and mental disorders will also increase the risk of falls. We therefore recommend that screening for mental illnesses such as depression be included when assessing risk of falls in the elderly. To summarise the abovementioned analyses, the Taiwan VAC can refer to the US VHA measurement-based care for related practices ${ }^{42}$ and establish a complete monitoring system to precisely track the mental health, sleep problems and medication use of veterans to protect against falls.

A health survey of the residents of veteran's care centres in Taiwan found that $73 \%$ of veterans had vision not exceeding 0.1, which implies that they would have difficulty reading books and newspapers. ${ }^{26}$ This study found that veterans with diseases of the eyes had a greater risk of falls than non-veterans, and among fall patients, significantly higher percentages of veterans had cataracts $(12.7 \%$ vs $4.7 \%$; $\mathrm{p}<0.001)$ and glaucoma $(2.3 \%$ vs $1.1 \%$, $\mathrm{p}<0.001)$ than non-veterans. Further analysis revealed that veterans with cataracts had 1.378 times the risk of falls of non-veterans with cataracts (adjusted $\mathrm{HR}=1.378$, 95\% CI 1.306 to $1.453, \mathrm{p}<0.001)$. Similarly, veterans with glaucoma had 1.414 times the risk of falls of non-veterans with glaucoma (adjusted HR=1.414, 95\% CI 1.259 to $1.588, \mathrm{p}<0.001)$. While research has indicated that cataracts are an independent risk factor for falls in veterans, ${ }^{14}$ this study found that cataracts (adjusted $\mathrm{HR}=1.322$, $\mathrm{p}<0.001,95 \%$ CI 1.237 to 1.412 ) are also a predictor of recurrent falls in veterans. Further research is needed to verify whether veterans' diseases of the eyes are a consequence of the long-term exposure of the lens to UV radiation while participating in field training or at other times during their period of service, or a result of poor control of chronic diseases, or are induced by the severity of their diseases.

The results of this study show that eye disease (including cataracts and glaucoma) is a risk factor for falls among veterans (online supplementary table S5), and cataracts is also a predictor of recurrent falls (online supplementary table S6). Meanwhile, the living environment (lighting equipment) may be a factor affecting falls as well. ${ }^{43}$ Therefore, the Taiwan VAC should help veterans seek medical attention at a hospital ophthalmology department periodically $^{44}$ and should also focus on improving the environment (indoor lighting equipment) to protect against falls. This study discovered that veterans had higher levels of all comorbidities/complications (including hypertension, cardiovascular disease, cerebrovascular disease, lung disease, arthritis, gastrointestinal disease, diabetes, liver disease, kidney disease, among others) than non-veterans. A 2013 cross-sectional study suggested that cerebrovascular disease and gouty arthritis are independent risk factors for falls in veterans, ${ }^{14}$ which is consistent with this study. Foreign research has also indicated that veterans over the age of 65 years have more comorbidities/complications than veterans under the age of 65 years. ${ }^{45}$ Our study findings indicate that among persons with comorbidities/complications, veterans have a greater risk of falls than non-veterans, which underscores the importance of chronic disease prevention and rehabilitation exercises as veterans age. 
This study made the further discovery that among fall-related injuries, veterans had a greater incidence of both falls from a height and falls at the same level than non-veterans. Furthermore, veterans had 1.29 times $(p<0.001)$ the risk of recurrent falls of non-veterans, and during the 2000-2013 period, each veteran had 4.07 falls, which was significantly greater than the falls of non-veterans (3.88 times). Moreover, the average hospital stay (9.13 days) and medical expenditures (NT\$59 000) of veterans with falls were both higher than those of non-veterans (8.77 days and NT\$58 000), and the percentage of veterans who died while hospitalised $(3.7 \%)$ was also higher than that of non-veterans $(2.8 \%)$ (online supplementary table S8). To summarise the foregoing research findings, veterans constitute a high-risk group for falls among the general elderly population and have relatively high medical utilisation after suffering falls.

The strengths of this study include a sufficiently large research sample and a tracking period of 14 years, as well as the ability to compare the risk of falls among veterans and non-veterans and confirm factors affecting falls in veterans. However, despite these strengths, this study also had the following limitations. First, this study was limited by the format of the data in the NHIRD and could not obtain other important information related to falls (such as the (widows or widowers), living environment (lighting equipment), patient weight, dietary intake, muscular endurance and degree of disability). Second, this study analysed inpatient files in the NHIRD and was unable to estimate the percentages of individuals who did not receive care or who only received outpatient/emergency care; thus, this study may have underestimated the number of cases.

\section{CONCLUSION}

Veterans had 1.252 times the risk of falls and 1.290 times the risk of recurrent falls of non-veterans. In addition, veterans also had longer inpatient stays and higher medical expenditures and death rates than non-veterans. Age (especially the 75-84years old age group), low urbanisation, comorbidities/complications, mental illness and diseases of the eyes were risk factors for falls in veterans, and depression and cataracts were predictors of recurrent falls. Apart from implementing preventive measures targeting high-risk groups, the responsible authorities should also seek to reduce the risk of falls among veterans by resolving their psychological and physiological issues.

Acknowledgements This study was supported by grants from Tri-Service General Hospital Research Foundation (TSGH-C108-003 to W-CC). This manuscript was translated into English by American Journal Experts.

Contributors All authors designed the study. Data analyses and interpretation were performed by H-JP and W-CC. SK and W-CC drafted and revised the manuscript. All authors read and approved the final manuscript.

Funding The authors have not declared a specific grant for this research from any funding agency in the public, commercial or not-for-profit sectors.

Competing interests None declared.
Patient consent for publication Not required.

Provenance and peer review Not commissioned; externally peer reviewed.

Data availability statement No data are available.

Open access This is an open access article distributed in accordance with the Creative Commons Attribution Non Commercial (CC BY-NC 4.0) license, which permits others to distribute, remix, adapt, build upon this work non-commercially, and license their derivative works on different terms, provided the original work is properly cited, appropriate credit is given, any changes made indicated, and the use is non-commercial. See: http://creativecommons.org/licenses/by-nc/4.0/.

\section{REFERENCES}

1. World Health Organization. Falls: fact sheet, 2018. Available: http:// www.who.int/en/news-room/fact-sheets/detail/falls [Accessed 14 Apr 2018].

2. Ministry of Health and Welfare, Taiwan. 2017 statistical results on causes of death in Taiwan. Available: https://www.mohw.gov.tw/cp16-41794-1.html [Accessed 16 Jun 2018].

3. Department of Veterans Affairs, Veteran Health Administration. Prepared by the National center for veterans analysis and statistics, 2018. Available: https://www.va.gov/vetdata

4. Ministry of Health and Welfare. Central health insurance, department insurance information open service. Available: https://data.nhi.gov. tw/Datasets/DatasetDetail.aspx?id=288\&Mid=A111026 [Accessed 14 Apr 2018].

5. Burns ER, Stevens JA, Lee R. The direct costs of fatal and non-fatal falls among older adults - United States. J Safety Res 2016;58:99-103.

6. Tinetti ME, Speechley M, Ginter SF. Risk factors for falls among elderly persons living in the community. N Engl J Med Overseas Ed 1988;319:1701-7.

7. linattiniemi $\mathrm{S}$, Jokelainen J, Luukinen $\mathrm{H}$. Falls risk among a very old home-dwelling population. Scand J Prim Health Care 2009;27:25-30.

8. Sleet DA, Moffett DB, Stevens J. Cdc's research portfolio in older adult fall prevention: a review of progress, 1985-2005, and future research directions. J Safety Res 2008;39:259-67.

9. Rubenstein LA, Stevens JA, Scott V. Interventions to prevent falls among older adults. In: Handbook of injury and violence prevention (1st editor). LLC: Springer Science+Business media, 2007: 37-53.

10. Clegg A, Young J, lliffe S, et al. Frailty in elderly people. The Lancet 2013;381:752-62.

11. Paliwal Y, Slattum PW, Ratliff SM. Chronic health conditions as a risk factor for falls among the community-dwelling us older adults: a Zero-Inflated regression modeling approach. Biomed Res Int 2017;2017

12. Hartholt KA, Becker ML, van der Cammen TJM. Drug-Induced falls in older persons: is there a role for therapeutic drug monitoring? Ther Adv Drug Saf 2016;7:39-42.

13. Chien W-C, Chung $\mathrm{C}-\mathrm{H}$, Lai $\mathrm{C}-\mathrm{H}$, et al. A retrospective populationbased study of injury types among elderly in Taiwan. Int $J$ Inj Contr Saf Promot 2014;21:3-8.

14. YC K, Liu ME, Tsai YF, et al. Associated factors for falls, recurrent falls, and injurious falls in aged men living in Taiwan veterans homes. Int J Gerontol 2013;7:80-4.

15. Chang MY, Lin CS, Tang YJ. The prevalence of metabolic syndrome and its relationship to mortality in male elderly of a veteran home in central Taiwan. Taiwan Geriatr Gerontol 2009;4:130-42.

16. Kung HW, HY L, Huang YC, et al. H.Relationship between depressive symptoms and health status for community-dwelling elderly veterans in the Yunlin-Chiayi area. Chang Gung Nursing 2014;25:243-56.

17. Lin SM, Lee IC. The study of the social support and the life satisfaction on the elderly veterans in Taichung County. Taiwan $J$ Gerontol Health Res 2005;1:172-87.

18. Chu HF, SC W. An analysis of factors associated with hospital utilization for senior veterans in Taiwan. Taiwan Journal of Public Health 2004;23:297-304.

19. Chao KC, Wang TY. A comparative study on the differences of medical utilization between aged veterans and non-veterans. Xuanzang Social Science Journal 2013;11:1-36.

20. National health insurance research database: introduction. Available: https://nhird.nhri.org.tw/brief_01.html [Accessed 3 Apr 2018].

21. Hsing AW, loannidis JPA. Nationwide population science: lessons from the Taiwan National health insurance research database. JAMA Intern Med 2015;175:1527-9.

22. National Health Insurance Administration, Ministry of Health and Welfare. Injury severity score (ISS). Available: https://www.nhi.gov. tw/Resource/webdata/Attach_16673_2_Attach_729_2_ISS\%E5\% 
A4\%96\%E5\%82\%B7\%E5\%9A\%B4\%E9\%87\%8D\%E5\%BA\%A6\% E5\%88\%86\%E6\%95\%B8\%E8\%A1\%A8\%E6\%A0\%BC970730.pdf [Accessed 5 Jul 2019].

23. National Health Insurance Administration, Ministry of Health and Welfare. National health insurance major injury coverage. Available: https://www.nhi.gov.tw/Resource/webdata/1059_2_10000406\%E9\% 87\%8D\%E5\%A4\%A7\%E5\%82\%B7\%E7\%97\%85\%E7\%AF\%84\% E5\%9C\%8D\%E8\%A1\%A8-\%E7\%BD\%AE\%E7\%B6\%B2\%E7\% AB\%99.pdf [Accessed 5 Jul 2019].

24. Wang Y-C, Lin F-G, Yu C-P, et al. Depression as a predictor of falls amongst institutionalized elders. Aging Ment Health 2012;16:763-70.

25. Boswell EB, Stoudemire A. Major depression in the primary care setting. Am J Med 1996;101:3S-9.

26. MS T. A survey of the residents' health status at a veteran's home in South Taiwan. Taiwan J Public Health 1996;15:97-107.

27. Chang C-Y, Chen W-L, Liou Y-F, et al. Increased risk of major depression in the three years following a femoral neck fracture-a national population-based follow-up study. PLoS One 2014;9:e89867.

28. Liu CY, Hung YT, Chuang YL, et al. Incorporating development stratification of Taiwan Townships into sampling design of large scale health interview survey. J Health Manage 2006;4:1-22.

29. Wang F-T, Chang Y, Chien W-C, et al. Injury and medical expenditure in emergency department visits of older veterans. Geriatr Gerontol Int 2016;16:1254-62.

30. Cheng IC, Tseng YM, Chien WC. Health service utilization and related factors of Taiwanese elderly fall inpatients in 2009. Taiwan J Gerontol Health 2011;71:55-71.

31. Department of Veterans Affairs. Veteran health administration. Available: https://www.vac.gov.tw/cp-1993-33712-1.html [Accessed 5 Jul 2019].

32. Cully JA, Jameson JP, Phillips LL, et al. Use of psychotherapy by rural and urban veterans. J Rural Health 2010;26:225-33.

33. Mott JM, Hundt NE, Sansgiry S, et al. Changes in psychotherapy utilization among veterans with depression, anxiety, and PTSD. PS 2014;65:106-12.

34. Kao S, Wang Y-C, Tzeng Y-M, et al. Interactive effect between depression and chronic medical conditions on fall risk in communitydwelling elders. Int Psychogeriatr 2012;24:1409-18.
35. Olenick M, Flowers M, Diaz VJ, et al. Us veterans and their unique issues: enhancing health care professional awareness. Adv Med Educ Pract 2015;6:635-9.

36. Tramonti F, Maestri M, Gronchi A, et al. Psychological well-being of patients with insomnia and its relationship with anxiety and depression. Psychol Health Med 2016;21:309-16.

37. Helbig AK, Döring A, Heier M, et al. Association between sleep disturbances and falls among the elderly: results from the German cooperative health research in the region of Augsburg-Age study. Sleep Med 2013;14:1356-63.

38. Allain $\mathrm{H}$, Bentué-Ferrer D, Polard E, et al. Postural instability and consequent falls and hip fractures associated with use of hypnotics in the elderly: a comparative review. Drugs Aging 2005;22:749-65.

39. Leipzig RM, Cumming RG, Tinetti ME. Drugs and falls in older people: a systematic review and meta-analysis: I. psychotropic drugs. J Am Geriatr Soc 1999;47:30-9.

40. Min Y, Kirkwood CK, Mays DP, et al. The effect of sleep medication use and poor sleep quality on risk of falls in community-dwelling older adults in the US: a prospective cohort study. Drugs Aging 2016;33:151-8.

41. Min Y, Nadpara PA, Slattum PW, et al. The association between sleep problems, sleep medication use, and falls in community-dwelling older adults: results from the health and retirement study 2010. J Aging Res 2016;2016

42. Resnick SG, Hoff RA. Observations from the National implementation of measurement based care in mental health in the Department of Veterans Affairs. Psychol Serv 2019.

43. Lin M-R, Wolf SL, Hwang H-F, et al. A randomized, controlled trial of fall prevention programs and quality of life in older fallers. J Am Geriatr Soc 2007:55:499-506.

44. Gillespie LD, Robertson MC, Gillespie WJ, et al. Interventions for preventing falls in older people living in the community. Cochrane Database Syst Rev 2012;85.

45. Luther SL, French DD, Powell-Cope G, et al. Using administrative data to track fall-related ambulatory care services in the Veterans administration healthcare system. Aging Clin Exp Res 2005;17:412-8. 